\title{
Acute radiation dermatitis in breast cancer patients: challenges and solutions
}

This article was published in the following Dove Press journal:

Breast Cancer - Targets and Therapy

5 May 2017

Number of times this article has been viewed

\author{
Adam J Kole' \\ Lauren Kole ${ }^{2}$ \\ Meena S Moran' \\ 'Department of Therapeutic \\ Radiology, ${ }^{2}$ Department of \\ Dermatology, Yale University \\ School of Medicine, New Haven, \\ CT, USA
}

Correspondence: Meena S Moran Department of Therapeutic Radiology, Yale University School of Medicine, 333 Cedar St, New Haven, CT 06520, USA Email meena.moran@yale.edu

\begin{abstract}
Nearly all women who receive radiotherapy (RT) for breast cancer experience some degree of radiation dermatitis. However, evidence describing the appropriate management of radiation dermatitis is often lacking or contradictory. Here, we summarize the available literature regarding radiation dermatitis causes, the presentation and timing of symptoms, methods for dermatitis assessment and prevention, and review evidence-based management strategies.

Keywords: breast cancer, radiotherapy, radiation dermatitis, skin toxicity
\end{abstract}

\section{Introduction}

Breast cancer is the most common female malignancy in the USA. Approximately 250,000 estimated new cases are diagnosed and over 40,000 annual deaths are reported each year. Breast cancer is the second leading cause of malignant deaths in American women. ${ }^{1}$ A large proportion of breast cancer patients receive adjuvant radiation therapy (RT) in either the breast conservation or the postmastectomy setting to improve locoregional recurrence rates and overall survival., ${ }^{2,3}$ Patients undergoing RT to the intact breast or chest wall with or without regional lymph nodes typically receive 4-6 weeks of treatment, with radiation dermatitis anticipated as the most common acute side effect. ${ }^{4,5}$ This review focuses on the causes of radiation dermatitis, summarizes the preventative measures, and discusses the strategies for the management of radiation-related skin toxicity.

\section{Radiation dermatitis: a historical perspective}

Soon after radiation was introduced as a therapeutic modality in the early $1900 \mathrm{~s}$, the effects of X-rays on skin were recognized as one of the major dose-limiting toxicities. ${ }^{6,7}$ Researchers began immediately examining techniques for reducing radiation-induced skin reactions. One of the earliest published examples comes from Gottwald Schwarz, who in 1909 showed that radiation injury to skin could be reduced by applying pressure to irradiated areas with direct compression. ${ }^{8}$

Initial radiobiologic discoveries pioneered by Regaud, Coutard, Reisner, Quimby, and others led to the realization that if radiation directed to the tumor is delivered in a fractionated manner, in which smaller daily doses are delivered to a higher total cumulative dose (instead of a large single fraction), the acute and late effects of radiation on the skin and other normal tissues are greatly reduced. ${ }^{6}$ Improved understanding of the repair mechanisms of normal tissue relative to tumor has demonstrated that fractionated treatment improves the therapeutic ratio by allowing for normal tissue repair while 
still causing tumor cell death. Historically, physicians who utilized radiation for therapeutic purposes used the skin on their forearms to measure the degree of radiation exposure. Termed "erythema dose", this calibration mechanism was used to determine the lowest radiation dose that produced erythema on the exposed skin to approximate the radiation dose delivered per fraction. ${ }^{9}$

The development of megavoltage X-ray machines in the 1950s was a major advancement in the field of radiation oncology. Earlier radiation techniques used orthovoltage units that were known to deposit maximum radiation dose at the patient skin surface. In contrast, cobalt-60 radiation units and linear accelerators producing X-ray beams with energies of $\geq 4$ MV were able to take advantage of a "skin-sparing" phenomenon, where higher energy X-rays resulted in lower doses to the skin. In fact, megavoltage $\mathrm{X}$-rays are known to deposit maximal radiation dose at a certain depth, often millimeters or centimeters below the skin surface. As radiation beam energy increases, the depth of maximal dose deposition also increases, thereby further lowering the dose to the skin. ${ }^{10}$

Despite these historic advancements in our understanding of RT and its effects on normal tissue, radiation dermatitis continues to be one of the most common side effects of modern RT.

\section{Pathophysiology}

The two main components of the skin are the superficial epidermis and the deeper dermis, each of which have unique structures and function and respond variably to radiation exposure.

\section{Anatomy and function}

The primary function of the skin, particularly the epidermis, is to provide a protective barrier for the body from physical, chemical, infectious, and thermoregulatory threats. The epidermis is composed of the following four histologic layers (from deepest to most superficial): stratum basale, stratum spinosum, stratum granulosum, and stratum corneum. ${ }^{11}$ Basal keratinocytes of the stratum basale are a stem cell population that asymmetrically divide to give rise to additional basal stem cells or daughter cells, which systematically differentiate into the more superficial epidermal layers. ${ }^{12}$ The process of keratinocyte maturation and migration to the stratum corneum takes approximately 2 weeks and ultimately generates an anucleated flattened layer of keratin. Additional cellular types within the epidermis include melanocytes and Langerhans cells.

The dermis, which lies deep to the epidermis and basement membrane, is primarily composed of a collagen network produced by dermal fibroblasts that provide the skin with structural integrity. ${ }^{11}$ The dermis contains various important cellular types that are not found in the epidermis. Rich vasculature and lymphatics within the dermis supply both the dermis and the overlying epidermis with nutrients. Immune cells such as macrophages and dermal dendritic cells survey the environment for foreign antigens and play an important role in wound healing. In addition, nerve endings, sebaceous glands, and hair follicles are all contained within the dermis. Impairment of proper skin function can lead to a loss of fluid and electrolyte balance; increased exposure of deeper tissues to dangerous chemicals, carcinogens, and infectious agents; and can disrupt core body temperature regulation.

\section{Possible mechanisms of injury}

High-energy X-rays delivered during RT produce direct and indirect ionization events that lead to damage of cellular macromolecules, most importantly in the form of double-stranded DNA breaks. ${ }^{6}$ Through this DNA damaging mechanism, RT affects all cellular types within the epidermis and dermis and leads to the clinical syndrome of radiation dermatitis. Within the epidermis, radiation-induced DNA damage disrupts the normal proliferation and differentiation of basal keratinocytes. ${ }^{13-15}$ As a result, differentiated epidermal keratinocytes are depleted, and maintenance of this physical barrier is lost.

Radiation effects in the dermis are more complex. Hair follicles and sebaceous glands are sensitive to relatively low doses of radiation and lead to the acute effects of hair loss and skin dryness. ${ }^{16}$ Microvascular injury within the dermis also contributes to both the acute and chronic skin effects of radiation. ${ }^{17,18}$ Proinflammatory cytokines and chemokines, such as interleukin (IL)-1, IL-6, IL-8, and tumor necrosis factor (TNF)-alpha, among others, have been found to play roles in immune cell activation, leukocyte transendothelial migration, and inflammatory edema. ${ }^{19-22}$ Mast cell degranulation and histamine release also further the immune response and contribute to the clinical radiation dermatitis syndrome. ${ }^{23}$ Radiation effects on dermal fibroblasts, mediated by transforming growth factor (TGF)-beta, are felt to be more important for late tissue fibrosis, rather than acute dermatitis. ${ }^{24,25}$

\section{Presentation and timing}

Radiation dermatitis develops in a deterministic, dosedependent manner with predictable timing., ${ }^{5,16,26,27}$ The acute phase of radiation dermatitis is typically defined as occurring within 30-90 days of radiation exposure. ${ }^{27,28}$ The most common skin changes seen as a result of acute radiation dermatitis are illustrated in Figure 1 and Table 1. 


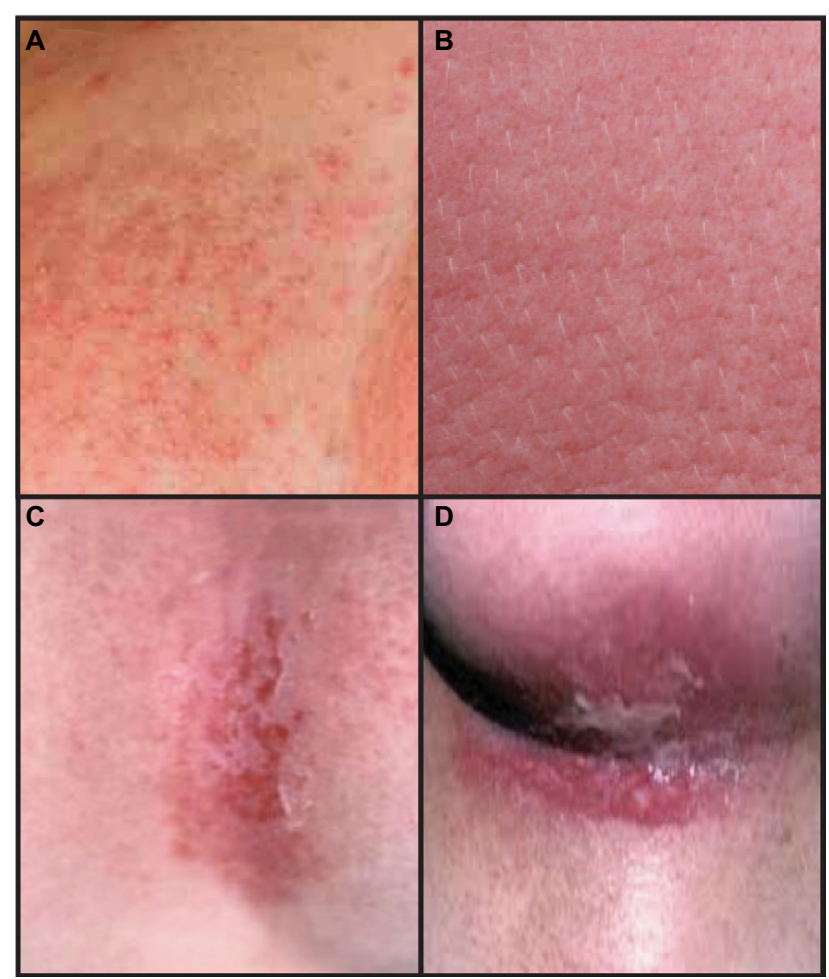

Figure I Common skin reactions in patients receiving breast radiation therapy. Notes: (A) Follicular reaction with pruritus. (B) Skin erythema and edema. (C) Dry desquamation in axillary fold. (D) Moist desquamation in inflammatory fold.

Table I Clinical symptoms of acute radiation dermatitis

\begin{tabular}{lll}
\hline Skin reaction & Onset & Dose threshold (Gy) \\
\hline Erythema & $7-10$ days & $6-10$ \\
Dry desquamation & 3-4 weeks & $20-25$ \\
Moist desquamation & 4+ weeks & $30-40$ \\
Ulceration & 5+ weeks & $>40$ \\
\hline
\end{tabular}

Mild erythema is typically the first clinically apparent skin change after breast radiation. Within hours of radiation exposure, an early, faint, and transient erythema can sometimes be appreciated. ${ }^{16}$ The most conventional skin reaction, however, occurs approximately 10-14 days after initiation of treatment and often will progressively worsen throughout the course of treatment. ${ }^{29}$ Reminiscent of a "sunburn", the skin reaction can evolve to include symptoms of edema, dryness, burning, itching, tenderness, and hyperpigmentation. Skin or nipple-areolar hyperpigmentation often occur approximately $2-3$ weeks after treatment initiation, ${ }^{27}$ particularly in patients with increased melanin content. If there are hair follicles in the irradiated field, epilation is also seen in this time frame. The dose ranges for these effects occur approximately between 6 and $20 \mathrm{~Gy}{ }^{5}$

Desquamation, either dry or moist, is typical of higher radiation doses and classically appears in the later portions of a radiation treatment course. Dry desquamation can occur at doses above 20 Gy and is characterized by peeling of dry, scaly skin and may not particularly add to patient symptomatology. Moist desquamation, however, is painful and a result of destruction and sloughing of dermal layers. It is also characterized by serous fluid drainage, or "weeping", which is typically only experienced after cumulative doses in excess of $30 \mathrm{~Gy}^{5}$ Moist desquamation often begins as small patches in skin folds and can progress to involve larger, confluent areas of irradiated skin. These symptoms are most pronounced in the axilla and inframammary fold and peak in intensity 1-2 weeks after the completion of the radiation treatment course. ${ }^{29-31}$

The resolution of acute dermatitis requires the repopulation of epidermal keratinocytes and reversal of the immune response cascade. Re-epithelialization begins at approximately day 10 and competes with ongoing radiation damage to maintain homeostasis of the epidermal layer. ${ }^{5,32}$ Once radiation treatments are complete, the majority of symptoms usually resolve 2-4 weeks following the end of treatment. ${ }^{33,34}$ Hyperpigmentation may last for several months but does eventually resolve over time. ${ }^{35}$ Late effects of radiation such as fibrosis or telangiectasias can appear months to years after the completion of radiation but are outside of the scope of this article.

\section{Assessment and scoring}

Several grading scales exist to aid in the reproducible quantification of acute radiation dermatitis. The Radiation Therapy Oncology Group/European Organization for Research and Treatment of Cancer (RTOG/EORTC) toxicity criteria and National Cancer Institute Common Toxicity Criteria for Adverse Events (NCI CTCAE) systems are the most commonly used (Table 2). 4,36,37

Since the majority of cases of breast radiation dermatitis fall within the RTOG/EORTC and NCI CTCAE range of grade 1 or grade 2 , additional scoring systems which are more nuanced have been explored to better evaluate radiation skin reactions. ${ }^{38}$ Examples include a modified CTCAE scale which subdivides grade 2 toxicities into three subcategories based on the presence of erythema, dry desquamation, or wet desquamation; ${ }^{39,40}$ a modified RTOG scale which subdivides grade 2 toxicities into two categories; ${ }^{41,42}$ the RadiationInduced Skin Reaction Assessment Scale (RISRAS) which individually scores the extent and severity of erythema, dry desquamation, moist desquamation, and necrosis; ${ }^{43,44}$ and the 10-point Catterall skin scoring profile. ${ }^{31,45}$

Patient-reported symptoms of radiation dermatitis are arguably more important than physician ratings. The RISRAS 
Table 2 Acute radiation dermatitis scoring systems

\begin{tabular}{|c|c|c|c|c|c|c|}
\hline & 0 & I & 2 & 3 & 4 & 5 \\
\hline CTCAE* & No change & $\begin{array}{l}\text { Faint erythema, dry } \\
\text { desquamation }\end{array}$ & $\begin{array}{l}\text { Moderate erythema or } \\
\text { edema, patchy moist } \\
\text { desquamation, confined } \\
\text { to skin folds and creases }\end{array}$ & $\begin{array}{l}\text { Moist desquamation in } \\
\text { areas other than skin } \\
\text { folds, bleeding induced } \\
\text { by minor trauma }\end{array}$ & $\begin{array}{l}\text { Life-threatening consequences, } \\
\text { full thickness skin necrosis/ } \\
\text { ulceration, spontaneous } \\
\text { bleeding, skin graft indicated }\end{array}$ & Death \\
\hline RTOG & No change & $\begin{array}{l}\text { Faint erythema, } \\
\text { dry desquamation, } \\
\text { epilation, decreased } \\
\text { sweating }\end{array}$ & $\begin{array}{l}\text { Tender or bright } \\
\text { erythema, moderate } \\
\text { edema, patchy moist } \\
\text { desquamation }\end{array}$ & $\begin{array}{l}\text { Moist desquamation } \\
\text { in areas other than } \\
\text { in skin folds, pitting } \\
\text { edema }\end{array}$ & $\begin{array}{l}\text { Ulceration, hemorrhage, } \\
\text { necrosis }\end{array}$ & Death \\
\hline
\end{tabular}

Notes: *Version 4.03. No changes are proposed for version 5.0.

Abbreviations: RTOG, Radiation Therapy Oncology Group; CTCAE, European Organization for Research and Treatment of Cancer.

noted above also incorporates a patient component which focus on skin tenderness, itchiness, burning, and functional activity. ${ }^{43}$ Six-point Likert scales quantifying symptoms are also in use. ${ }^{31}$ Other quality of life assessments also exist, such as the EORTC breast cancer-specific quality of life questionnaire (QLQ-BR-23) and the Functional Assessment of Cancer Therapy-Breast (FACT-B). ${ }^{46,47}$ Only a small minority of the latter assessments are specific to symptoms of breast-related radiation dermatitis, however.

\section{Patient and treatment-related risk factors}

Risk factors that predispose to the development of acute breast dermatitis have been carefully studied. These can be generally divided to patient characteristics or radiation treatment technique categories.

\section{Patient factors}

Larger breast size was among the earliest patient characteristics to be identified as a risk factor for acute skin toxicity. Prospectively confirming our general clinical experience when treating smaller versus larger breast cup sizes, a study at the Royal Marsden Hospital demonstrated that women with larger breast sizes were nearly five times more likely to experience acute skin reaction, ${ }^{30} \mathrm{a}$ finding that has since been consistently reproduced by others..$^{29,34,48}$ Patient body mass index (BMI) has also been shown to be independently associated with increased risk of acute skin toxicity, including moist desquamation..$^{40,49}$ As mentioned above, the worst skin reactions are seen in the inframammary and axillary folds. It is hypothesized that a greater self-bolusing effect increases the toxicity to these regions, where the skin-sparing effects of megavoltage radiation beams are negated due to the buildup of skin-on-skin. This is particularly important in patients with large breast size and/or high BMIs as the areas with skin-on-skin overlap are the greatest. As detailed in the next section, increased field size/separation in these patients also can lead to dosimetric effects.

Additional patient factors such as the degree of friction due to normal arm movement, the texture and types of clothing items worn, and a build-up of perspiration can contribute to skin reaction. Racial differences and menopausal status have also been linked to radiation dermatitis risk, with significantly higher rates of moist desquamation demonstrated in black and postmenopausal women in one prospective study. ${ }^{39}$ The effects of smoking on radiation induced skin reactions have been mixed, and no conclusions can be drawn from the existing data. ${ }^{40,50}$ Lastly, rare genetic syndromes with associated underlying mutations in genes specifically involved in the DNA-repair response can result in severe acute radiosensitivity. Examples of such syndromes include Ataxia-Telangiectasia, Nijmegen Breakage Syndrome, and Fanconi Anemia. ${ }^{51}$

\section{Treatment-related factors}

A major evolution in breast radiation treatment stemmed from the discovery that techniques that deliver a more uniform, homogenous radiation dose across breast tissue result in significantly less acute and long-term skin toxicity. Studies have now established that compared to older twodimensional (2D) techniques (for which radiation treatment planning was generated using a single axial cut across the central axis, or mid-center of the breast), three-dimensional (3D) treatment planning significantly diminishes radiationinduced skin reactions. 3D techniques account for changes in breast contour above and below the central axis to reduce inherent radiation "hot-spots". These "hot-spots" regions, where radiation is delivered above the prescription dose, are known to increase the risk of radiation dermatitis, as are breast regions receiving beyond $45 \mathrm{~Gy} .{ }^{49,52}$

"Field-in-field" 3D techniques or breast intensitymodulated radiation therapy (IMRT) are two methods that 
allow for multiple smaller radiation fields (within larger traditional tangential fields) to be used to decrease breast inhomogeneity. The use of these techniques is now considered standard-of-care for all centers that have 3D treatment capabilities. Prospective trials of 3D/IMRT technique have shown improved rates of hyperpigmentation, edema, and moist desquamation; ${ }^{29,53}$ diminished durations and severity of radiation dermatitis reactions in the acute setting $;{ }^{38}$ and have resulted in significantly reduced long-term skin changes and fibrosis that are associated with breast radiation. ${ }^{54}$

Alternative treatment techniques, such as prone positioning, have also been explored with regards to the ability to improve breast dose homogeneity and acute dermatitis outcomes. Indeed, prone positioning for large-breasted women improves dose distribution, reduces radiation "hot-spots", and lowers the incidence of breast dermatitis including moist desquamation. ${ }^{55}$ Prone positioning can be combined with 3D/ IMRT techniques for optimal dose distribution (Figure 2). Of note, given the increased cost and uncertain long-term disease control outcomes when compared to 3D treatment techniques, the expanding use of IMRT for the treatment of early-stage breast cancer has been criticized. ${ }^{56}$

Lastly, the use of hypofractionationated breast radiation is increasing. ${ }^{57}$ Hypofractionation delivers a slightly higher daily dose of radiation to an overall biologically equivalent total dose, which ultimately results in shorter treatment time (from 5-6 to 3-4 weeks). Based on radiobiologic models of radiation response of breast tumor cells and late normal breast tissue effects, prospective randomized trials were designed to assess the use of shorter fractionation schemas for efficacy and toxicity. These trials have now consistently demonstrated that the use of hypofractionated whole breast radiation in breast cancer results in similar long-term outcomes to that of standard fractionation, without any evidence of increased toxicity with the higher daily fraction size. ${ }^{58-60}$ Furthermore, differences in acute radiation effects have been prospectively evaluated for hypofractionated versus standard fractionated treatment courses, and in fact, these data suggest that hypofractionation portends improvements in the rates of dermatitis, pruritus, hyperpigmentation, and breast pain in the acute setting. ${ }^{61}$

\section{Management challenges}

As detailed below, many randomized trials have been performed in an attempt to identify ideal management practices for the prevention and treatment of radiation dermatitis. Despite the increasing availability of randomized evidence, many factors have limited the applicability of these studies to the general breast cancer population. A majority of the literature is from small, single-institution studies with limited power to detect differences between treatment and control arms. A lack of consensus on what constitutes standard of care causes study control arms to vary between no treatment and one of many placebo creams or ointments. Other studies have directly compared two treatments without a no treatment or placebo group, thus comparisons across trials has been difficult. Furthermore, the use of different dermatitis assessment tools and the inconsistent selection of study end-points has added to the complexity. Finally, all of these studies are challenged with the failure to control for variables that are known to predispose to radiation dermatitis such as breast size, BMI, or radiation treatment techniques.

Historically, recommendations for the prevention and treatment of radiation dermatitis were based on the personal and anecdotal experiences of radiation oncologists, radiation therapy nurses, or patient preferences. In 2006, a systematic
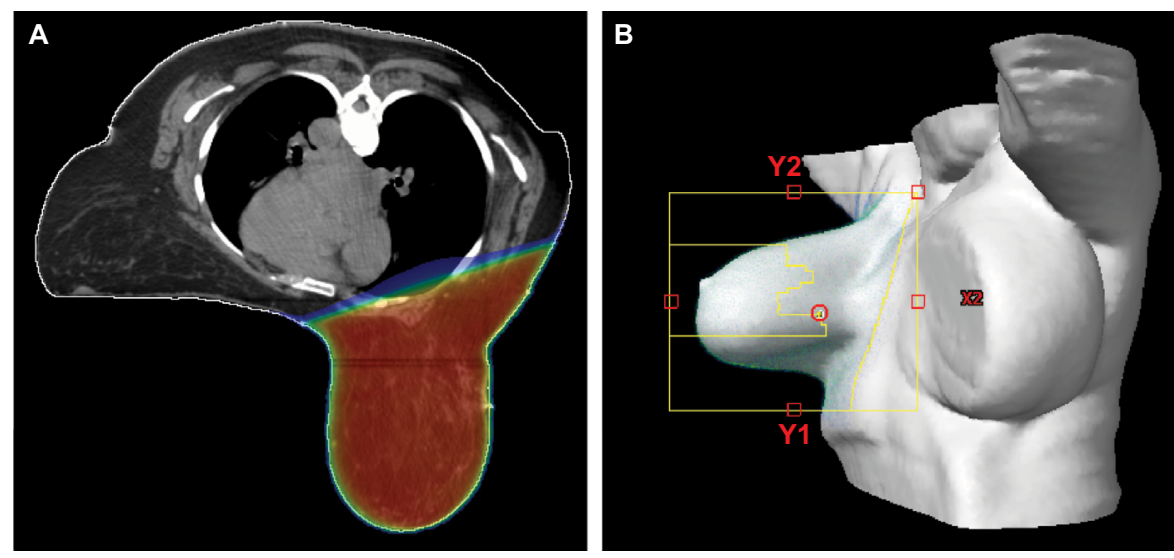

Figure 2 Illustration of a three-dimensional prone radiation treatment plan for a patient with large breast size.

Notes: (A) Homogeneous radiation dose is shown in dose color wash. Red indicates areas receiving prescription dose; blue indicates area of lowest dose. (B) Beam's eye view of a single radiation subfield, designed as part of the "field-in-field" treatment design in the prone position. 
review published by the Cancer Care Ontario's Supportive Care Guidelines Group concluded there was insufficient evidence to support the use of any topical agent for radiation dermatitis prevention. ${ }^{62}$ Subsequently, additional studies have been added to the body of literature and have been informative for identifying general principles of skin care during RT treatment. While the available literature has not clearly defined optimal treatment of radiation dermatitis based on high-level evidence, it is important to recognize that recommendations in use today, in practice, have not been found to cause any harm or interact negatively with RT.

\section{Evidence for radiation dermatitis prevention}

There are several categories of agents used for prevention of radiation-induced skin reactions that have been evaluated in breast cancer patients. The vast majority are used to provide anti-inflammatory, antimicrobial, and moisturizing properties, though their efficacy in prevention of skin reactions has not been consistently demonstrated across studies.

\section{Topical steroids}

Multiple prospective randomized trials have established that topical corticosteroids are effective for diminishing radiation dermatitis in breast cancer patients. An early study in 2001 by Boström et al tested the effect of mometasone furoate for radiation dermatitis prevention. Of the 49 patients randomized to receive either intermittent mometasone or a placebo emollient cream, physician-rated levels of erythema were statistically lower in patients receiving topical steroid therapy. ${ }^{63}$ These results have been validated in two larger, more recent studies that also tested the efficacy of mometasone furoate. ${ }^{41,64}$ Importantly, the confirmatory studies were performed using validated assessment tools and showed improvements in patient-reported outcomes with mometasone use during RT.

Similarly, patients using betamethasone were found in randomized trials to have diminished dermatitis when compared with placebo. ${ }^{65,66}$ The preventative effect of betamethasone on radiation dermatitis has been seen in both conventional and hypofractionated radiation settings. ${ }^{67}$ Mometasone and betamethasone have not been directly compared to one another.

\section{Nonsteroidal agents}

In contrast to recent studies that have consistently shown improvements in radiation dermatitis with topical corticosteroids, many nonsteroidal agents have failed to show a clear benefit when tested prospectively. A large study of
350 patients tested the use of sucralfate or aqueous cream compared to no cream in patients with multiple cancer types, of which $75 \%$ of patients had breast cancer. ${ }^{68}$ Mean weekly RTOG dermatitis scores were not improved with the use of either cream compared to no treatment. Patient-reported symptoms were also not significantly different between the three arms. Multiple studies have shown that the use of aloe vera gel is ineffective in reducing both physician and patient-reported acute skin reactions when compared with placebo or no treatment. ${ }^{31,69}$ In one study, patients actually had worse breast pain and dry desquamation when using aloe vera. ${ }^{70}$ Hyaluronic acid similarly worsened rates of grade $2+$ dermatitis when compared with control petrolatum gel in one trial, although others have shown no difference between hyaluronic acid and simple emollient. ${ }^{71,72}$

Some nonsteroidal agents have shown promise. Silver sulfadiazine cream 3 days per week during RT and for 1 week after was shown to result in overall reduced RTOG dermatitis rates compared to a control no intervention group. ${ }^{73}$ Lower rates of acute grade $2+$ dermatitis have been seen with calunda ointment, extracted from the Calendula officinalis plant and traditionally used as a topical anti-inflammatory agent in wound healing, when compared to trolamine. ${ }^{74}$ Furthermore, these data suggest a reduction in breast pain and need for treatment breaks with calendula use. Unfortunately, these benefits of calendula were not replicated in a more recent larger trial. ${ }^{75}$ Similarly, the use of trolamine, another topical anti-inflammatory lotion, was compared to best supportive care in a study of 172 patients breast cancer patients and was unable to demonstrate any differences in time to radiation dermatitis, maximum RTOG dermatitis score, or duration of dermatitis. ${ }^{34}$

\section{Barrier products for dermatitis prevention}

Initial prevention studies of spray-on barrier films such as $3 \mathrm{M}$ Cavilon No-Sting Barrier Film were shown to reduce rates of moist desquamation, pain, and pruritus when compared to glycerin creams. ${ }^{76}$ Mepitel Film also showed promise as a preventative barrier product for reducing moist desquamation rates. ${ }^{77}$ Due to the inherent physically apparent differences between the barrier films and creams, blinding of patients or physicians is not possible. However, an attempt was made to evaluate these barrier methods in a blinded manner by a study that compared glycerin cream to $3 \mathrm{M}$ Cavilon Durable Barrier Cream, both specifically designed as cream-based applications. Unfortunately, however, this study also failed to demonstrate any differences in skin reactions between the two film and placebo products. ${ }^{78}$ 


\section{Preclinical data}

Preclinical models are being used to discover novel strategies for prevention of radiation dermatitis. Pravastatin, better known for its effects on cholesterol levels, has known anti-inflammatory properties via inhibition of endothelial cell activation, cytokine production, and leukocyte migration. When tested in cell culture and mouse models of radiation-induced inflammation and radiation skin injury, pravastatin has shown promise as a future therapy. ${ }^{79,80}$ Plant derivatives curcumin and esculentoside $\mathrm{A}$ have been found to reduce acute cutaneous damage in irradiated mice..$^{81,82}$ Most recently, a study of topical adrenergic vasoconstrictors such as epinephrine were shown to confer a dose-dependent prevention of radiation dermatitis in mice, with the highest doses causing complete protection. ${ }^{83}$ Whether these findings will translate to humans during a course of fractionated daily radiation remains unclear.

\section{Management of skin during breast RT}

Treatment of radiation dermatitis is recommended in patients who develop symptoms, despite preventative measures, particularly if moist desquamation occurs. However, in contrast to the relatively large number of clinical trials in the context of radiation dermatitis prevention, fewer trials have been performed for radiation dermatitis treatment. Management guidelines have been published to assist clinicians with evidence-based interventions for radiation dermatitis. ${ }^{62,84,85}$ Not surprisingly, given the limited high-quality evidence for or against many of the available treatment options, disagreements regarding optimal management remain. Nevertheless, general guiding principles can be followed, as reviewed below, and summarized in Table 3 .

\section{Skin washing}

Historically, concerns that washing with soap and water could cause mechanical trauma and worsen of radiation dermatitis resulted in recommendations against washing in the radiation treatment fields. Subsequently, these long-standing recommendations have been challenged in randomized trials. The first of these trials randomized patients to no washing, washing with water alone, or washing with soap and water. Patients who used soap and water had significant reductions in itching at the end of treatment and reduced erythema and desquamation scores $6-8$ weeks following treatment, findings that were independent of other confounding factors such as bolus use. ${ }^{86}$ The second study randomized approximately 100 patients to washing with soap and water versus no washing and reported higher incidence of moist desquamation in the
Table 3 Summary of recommendations for radiation dermatitis evaluation and treatment

Preradiotherapy assessment:

Screen patient for radiation hypersensitivity syndromes

Assess for use of medications (eg, chemotherapy) with potential to cause dermatitis

Examine patient for baseline RTOG/CTCAE dermatitis score

Patient recommendations during treatment:

Protect skin from sun exposure

Minimize skin trauma from excessive movement, exposure to extreme temperatures, or adhesives

Gently wash skin with mild soap and water

Apply deodorant/antiperspirant as needed

Radiation treatment planning:

Three-dimensional dosimetric planning with use of field-in-field or IMRT techniques

Improve dose homogeneity to minimize "hot spot" regions

Consider prone positioning for large-breasted women

Consider hypofractionated treatment if otherwise indicated

Practices for radiation dermatitis prevention and treatment:

Skin emollients (not immediately before RT)

Topical steroids (eg, mometasone, betamethasone) for prevention

Consider nonsteroidal agents (eg, silver sulfadiazine, calendula ointment, barrier films)

Consider protective dressings for areas of moist desquamation

Monitor for and treat secondary infections if necessary

Provide reassurance, monitor symptoms for resolution

Abbreviations: RTOG/CTCAE, Radiation Therapy Oncology Group/European Organization for Research and Treatment of Cancer; IMRT, intensity-modulated radiation therapy; RT, radiotherapy.

no washing group (33\% vs. $14 \%$ ) and higher median scores for pain, itching, and burning, although these results were not statistically significant. ${ }^{87}$

Although the data supporting the use of soap and water in the radiation fields are somewhat limited, recommendations have nevertheless evolved such that patients are commonly advised to wash their skin daily with warm water and soap while avoiding scrubbing of the skin. Generally, the use of mild $\mathrm{pH}$-neutral or nonalkaline soaps is recommended ${ }^{88}$ When recommending specific brands of soaps, one historic study conducted in the late 1970s evaluated the irritating effects of 18 different soaps using a soap chamber and found the mildest to be Dove (Unilever, London, UK) ${ }^{89}$ Recommendation of this soap (unscented) is still in practice today.

\section{Deodorant and antiperspirant use}

The use of deodorants and antiperspirants were also historically discouraged for breast cancer patients as it was felt that the metallic-based formulations would increase the skin reaction when interacting with radiation, and furthermore, that the actual application could potentially create a bolus effect and increase skin dose. An important study by Burch et al assessed the surface dose of 15 solid, 
roll-on, and spray deodorant products and found no increase in surface dose with normal application, although higher surface doses did result from "thick application", which was defined as five times the normal application thickness. Furthermore, the authors challenged the previous assumptions that products containing magnesium, aluminum, or zinc would increase skin reaction by demonstrating no difference between metallic and nonmetallic deodorant products. ${ }^{90}$ Subsequently, controlled studies assessing the toxicity of deodorant use during breast radiation have consistently found no evidence of worse skin outcomes with deodorant use, changing the paradigm of prohibiting deodorant use during radiation. ${ }^{91-94}$

Based on these and other findings, it is generally felt that any enhanced skin reaction with normal use of deodorant products use may be related to the irritating chemical ingredients within the product itself, rather than the metallic content or bolus effect when applied with standard thickness..$^{95,96}$ Hence, usual hygiene with washing and the use of a deodorant are labeled as "recommended for practice" by the Oncology Nursing Society's Putting Evidence into Practice (PEP). ${ }^{84}$

\section{Barrier products for dermatitis treatment}

Moist environments promote wound healing by increasing the rate of tissue re-epithelialization. ${ }^{97}$ Cutaneous barriers are commonly used as they provide moisture and protect skin from developing secondary infections. Conflicting results from prospective comparisons of dressings, however, have not conclusively identified a standard treatment. Several studies have directly compared hydrocolloid dressings to gentian violet, an anti-microbial solution historically used for open wounds. While one study showed a significant reduction in the time to skin healing with hydrogel dressings (12 days vs. $>30$ days), ${ }^{98}$ other studies have not shown a difference. ${ }^{99}$ A separate comparison of hydrogel dressings versus dry dressings concluded that healing times were prolonged with hydrogel dressings. ${ }^{50}$ For erythema without desquamation, Mepilex dressings reduced skin erythema severity compared to aqueous cream alone. ${ }^{44}$ For the rare instance of radiation toxicity with deep dermal involvement, literature from the breast oncology field is limited. Such wounds should be treated using thermal burn paradigms, with biologic dressings such as AlloDerm.

\section{Management of desquamation}

In some patients, desquamation may occur irrespective of use of radiation delivery techniques to reduce skin reactions and diligence with prophylactic skin management methods during the course of RT. In these instances, the classification of the desquamation as either moist or dry is critical to its management. Dry desquamation, which is commonly associated with surface flaking of the stratum corneum, is in and of itself not a cause of concern but should be moisturized and kept clean and dry.

In some cases, dry desquamation can progress to moist desquamation, which characteristically demonstrates moist exudates in the desquamated portions of the irradiated skin. In this instance, it is important to assess and document the size of the desquamated area and its location(s), the type of tissue at the wound base (necrotic, granular, or eschar), and the presence and amount of any exudate. Patients should be treated with saline soaks using normal saline compresses up to four times daily. ${ }^{100}$ The use of moisture-retentive, barrier ointments after each saline soak, such as aquaphor, use of hydrogels, and use of absorbent dressings over nonadherent dressings are encouraged. Open areas can similarly be protected with nonadherent dressings to provide protection and diminish friction.

Furthermore, patients should be monitored closely and be evaluated daily when experiencing moist desquamation, as signs and symptoms can change rapidly over the course of hours to days. Patients should be observed for clinical signs of infection such as fever, foul-smelling or purulent odor, drainage, and/or swelling or pain extending outside the treatment area. Pain can be managed with analgesics (over the counter and/or prescription) based on the level of symptoms as assessed by the caregiver. For signs of infection, wounds and discharge should be cultured, and antibiotics should be empirically started until culture results are received.

\section{Conclusion}

Despite our increasing awareness and understanding of the side effects of radiation treatment in breast cancer, radiation dermatitis continues to be among the most common side effects. In order to effectively manage patients with radiation dermatitis, one must be aware of the expected appearance and timing of symptoms, the appropriate scoring systems for properly monitoring symptom severity over time, and should follow evidence-based guidelines for treatment when possible. Future therapies that may become available for radiation dermatitis will need to be thoroughly tested in welldesigned randomized trials to properly identify best practices.

\section{Disclosure}

The authors report no conflicts of interest in this work. 


\section{References}

1. Sie gel RL, Miller KD, Jemal A. Cancer statistics, 2016. CA Cancer J Clin. 2016;66(1):7-30.

2. Early Breast Cancer Trialists' Collaborative Group; Darby S, McGale P, et al. Effect of radiotherapy after breast-conserving surgery on 10-year recurrence and 15-year breast cancer death: meta-analysis of individual patient data for 10,801 women in 17 randomised trials. Lancet. 2011;378(9804):1707-1716.

3. Early Breast Cancer Trialists' Collaborative Group; McGale P, Taylor C, et al. Effect of radiotherapy after mastectomy and axillary surgery on 10-year recurrence and 20-year breast cancer mortality: meta-analysis of individual patient data for 8135 women in 22 randomised trials. Lancet. 2014;383(9935):2127-2135.

4. Fowble B, Park C, Yuen F. Breast cancer. In: Fowble B, Yom SS, Yuen F, Arron S, editors. Skin Care in Radiation Oncology A Practical Guide. Springer International Publishing: 2016:93-122.

5. Ryan JL. Ionizing radiation: the good, the bad, and the ugly. J Invest Dermatol. 2012;132(3 pt 2):985-993.

6. Zeman EM. The biological basis of radiation oncology. In: Gunderson LL, Tepper JE, Bogart JA, editors. Clinical Radiation Oncology. 4th ed. Philadelphia, PA; 2016:2-40.

7. Quimby E, Maccomb W. Further studies on the rate of recovery of human skin from the effects of roentgen or gamma rays. Radiology. 1937; 29:305-312.

8. Kaplan HS. Historic milestones in radiobiology and radiation therapy. Semin Oncol. 1979;6(4):479-489.

9. Khare P, Nair P, Khare A, Singh V, Chatterjee R. The road to radiation protection: a rocky path. J Clin Diagn Res. 2014;8(12):ZE01-ZE04.

10. Bourland JD. Radiation oncology physics. In: Gunderson LL, Tepper JE, Bogart JA, editors. Clinical Radiation Oncology. 4th ed. Philadelphia, PA; 2016:93-147.

11. Vandergri T, Bergstresser P. Anatomy and physiology. In: Bolognia J, Jorizzo JL, Schaffer JV, editors. Dermatology. 3rd ed. Philadelphia, PA: Elsevier Saunders; 2012:43-54.

12. Herst PM. Protecting the radiation-damaged skin from friction: a mini review. J Med Radiat Sci. 2014;61(2):119-125.

13. Liu K, Kasper M, Trott KR. Changes in keratinocyte differentiation during accelerated repopulation of the irradiated mouse epidermis. Int J Radiat Biol. 1996;69(6):763-769.

14. Schmuth M, Sztankay A, Weinlich G, et al. Permeability barrier function of skin exposed to ionizing radiation. Arch Dermatol. 2001;137(8): 1019-1023.

15. Trott KR, Shirazi A, Heasman F. Modulation of accelerated repopulation in mouse skin during daily irradiation. Radiother Oncol. 1999;50(3):261-266.

16. Koenig TR, Wolff D, Mettler FA, Wagner LK. Skin injuries from fluoroscopically guided procedures: part 1, characteristics of radiation injury. AJR Am J Roentgenol. 2001;177(1):3-11.

17. Archambeau JO, Ines A, Fajardo LF. Response of swine skin microvasculature to acute single exposures of $\mathrm{X}$ rays: quantification of endothelial changes. Radiat Res. 1984;98(1):37-51.

18. Hopewell J, Calvo W, Jaenke R, Reinhold H, Robbins M, Whitehouse E. Microvasculature and Radiation Damage. In: Hinkelbein W, Bruggmoser G, Frommhold H, Wannenmacher M, editors. Acute and Long-Term Side-Effects of Radiotherapy Biological Basis and Clinical Relevance. Berlin: Springer; 1993:1-16.

19. Muller K, Meineke V. Radiation-induced alterations in cytokine production by skin cells. Exp Hematol. 2007;35(4 Suppl 1):96-104.

20. Petit-Frere C, Capulas E, Lyon DA, et al. Apoptosis and cytokine release induced by ionizing or ultraviolet $B$ radiation in primary and immortalized human keratinocytes. Carcinogenesis. 2000;21(6):1087-1095.

21. Beetz A, Messer G, Oppel T, van Beuningen D, Peter RU, Kind P. Induction of interleukin 6 by ionizing radiation in a human epithelial cell line: control by corticosteroids. Int J Radiat Biol. 1997;72(1):33-43.

22. Hallahan DE, Spriggs DR, Beckett MA, Kufe DW, Weichselbaum RR. Increased tumor necrosis factor alpha mRNA after cellular exposure to ionizing radiation. Proc Natl Acad Sci USA. 1989;86(24):10104-10107.
23. Muller K, Meineke V. Radiation-induced mast cell mediators differentially modulate chemokine release from dermal fibroblasts. J Dermatol Sci. 2011;61(3):199-205.

24. Martin M, Lefaix J, Delanian S. TGF-beta1 and radiation fibrosis: a master switch and a specific therapeutic target? Int J Radiat Oncol Biol Phys. 2000;47(2):277-290.

25. Pohlers D, Brenmoehl J, Loffler I, et al. TGF-beta and fibrosis in different organs - molecular pathway imprints. Biochim Biophys Acta. 2009; 1792(8):746-756.

26. Mendelsohn FA, Divino CM, Reis ED, Kerstein MD. Wound care after radiation therapy. Adv Skin Wound Care. 2002;15(5):216-224.

27. Brown KR, Rzucidlo E. Acute and chronic radiation injury. J Vasc Surg. 2011;53(1 Suppl):15S-21S.

28. Harper JL, Franklin LE, Jenrette JM, Aguero EG. Skin toxicity during breast irradiation: pathophysiology and management. South Med J. 2004;97(10):989-993.

29. Pignol JP, Olivotto I, Rakovitch E, et al. A multicenter randomized trial of breast intensity-modulated radiation therapy to reduce acute radiation dermatitis. J Clin Oncol. 2008;26(13):2085-2092.

30. Fernando IN, Ford HT, Powles TJ, et al. Factors affecting acute skin toxicity in patients having breast irradiation after conservative surgery: a prospective study of treatment practice at the Royal Marsden Hospital. Clin Oncol. 1996;8(4):226-233.

31. Hoopfer D, Holloway C, Gabos Z, et al. Three-arm randomized phase III trial: quality aloe and placebo cream versus powder as skin treatment during breast cancer radiation therapy. Clin Breast Cancer. 2015; 15(3):e181-e184.

32. McQuestion M. Evidence-based skin care management in radiation therapy: clinical update. Semin Oncol Nurs. 2011;27(2):e1-e17.

33. Pignol JP, Vu TT, Mitera G, Bosnic S, Verkooijen HM, Truong P. Prospective evaluation of severe skin toxicity and pain during postmastectomy radiation therapy. Int J Radiat Oncol Biol Phys. 2015;91(1):157-164.

34. Fisher J, Scott C, Stevens R, et al. Randomized phase III study comparing Best Supportive Care to Biafine as a prophylactic agent for radiation-induced skin toxicity for women undergoing breast irradiation: Radiation Therapy Oncology Group (RTOG) 97-13. Int J Radiat Oncol Biol Phys. 2000;48(5):1307-1310.

35. Buchholz TA. Radiation therapy for early-stage breast cancer after breast-conserving surgery. $N$ Engl J Med. 2009;360(1):63-70.

36. Cox JD, Stetz J, Pajak TF. Toxicity criteria of the Radiation Therapy Oncology Group (RTOG) and the European Organization for Research and Treatment of Cancer (EORTC). Int J Radiat Oncol Biol Phys. 1995; 31(5):1341-1346.

37. National Cancer Institute. Common Terminology Criteria for Adverse Events v4.0. NIH; 2009. NIH publication \# 09-7473. Available from: https://ctep.cancer.gov/protocolDevelopment/electronic_applications/ ctc.htm. Accessed July 10, 2016.

38. Freedman GM, Li T, Nicolaou N, Chen Y, Ma CC, Anderson PR. Breast intensity-modulated radiation therapy reduces time spent with acute dermatitis for women of all breast sizes during radiation. Int J Radiat Oncol Biol Phys. 2009;74(3):689-694.

39. Wright JL, Takita C, Reis IM, Zhao W, Lee E, Hu JJ. Racial variations in radiation-induced skin toxicity severity: data from a prospective cohort receiving postmastectomy radiation. Int J Radiat Oncol Biol Phys 2014;90(2):335-343.

40. Twardella D, Popanda O, Helmbold I, et al. Personal characteristics, therapy modalities and individual DNA repair capacity as predictive factors of acute skin toxicity in an unselected cohort of breast cancer patients receiving radiotherapy. Radiother Oncol. 2003;69(2):145-153.

41. Hindley A, Zain Z, Wood L, et al. Mometasone furoate cream reduces acute radiation dermatitis in patients receiving breast radiation therapy: results of a randomized trial. Int J Radiat Oncol Biol Phys. 2014;90(4): 748-755.

42. Porock D, Kristjanson L, Nikoletti S, Cameron F, Pedler P. Predicting the severity of radiation skin reactions in women with breast cancer. Oncol Nurs Forum. 1998;25(6):1019-1029.

43. Noble-Adams R. Radiation-induced skin reactions. 2: development of a measurement tool. Br J Nurs. 1999;8(18):1208-1211. 
44. Diggelmann KV, Zytkovicz AE, Tuaine JM, Bennett NC, Kelly LE, Herst PM. Mepilex Lite dressings for the management of radiationinduced erythema: a systematic inpatient controlled clinical trial. $\mathrm{Br}$ J Radiol. 2010;83(995):971-978.

45. Catterall M, Rogers C, Thomlinson RH, Field SB. An investigation into the clinical effects of fast neutrons. Methods and early observations. Br J Radiol. 1971;44(524):603-611.

46. Sprangers MA, Groenvold M, Arraras JI, et al. The European Organization for Research and Treatment of Cancer breast cancer-specific quality-of-life questionnaire module: first results from a three-country field study. J Clin Oncol. 1996;14(10):2756-2768.

47. Brady MJ, Cella DF, Mo F, et al. Reliability and validity of the functional assessment of cancer therapy-breast quality-of-life instrument. J Clin Oncol. 1997;15(3):974-986.

48. Back M, Guerrieri M, Wratten C, Steigler A. Impact of radiation therapy on acute toxicity in breast conservation therapy for early breast cancer. Clin Oncol. 2004;16(1):12-16.

49. Rutter C, Qin L, Higgins S, Moran M, Evans S. Dosimetric and clinical predictors of the development of moist desquamation in breast cancer irradiation. J Radiat Oncol. 2014;3(2):147-152.

50. Macmillan MS, Wells M, MacBride S, Raab GM, Munro A, MacDougall H.Randomized comparison of dry dressings versus hydrogel in management of radiation-induced moist desquamation. Int $J$ Radiat Oncol Biol Phys. 2007;68(3):864-872.

51. Pollard JM, Gatti RA. Clinical radiation sensitivity with DNA repair disorders: an overview. Int J Radiat Oncol Biol Phys. 2009;74(5): 1323-1331.

52. Chen MF, Chen WC, Lai CH, Hung CH, Liu KC, Cheng YH. Predictive factors of radiation-induced skin toxicity in breast cancer patients. BMC Cancer. 2010;10:508.

53. Harsolia A, Kestin L, Grills I, et al. Intensity-modulated radiotherapy results in significant decrease in clinical toxicities compared with conventional wedge-based breast radiotherapy. Int J Radiat Oncol Biol Phys. 2007;68(5):1375-1380.

54. Donovan E, Bleakley N, Denholm E, et al; Breast Technology Group. Randomised trial of standard 2D radiotherapy (RT) versus intensity modulated radiotherapy (IMRT) in patients prescribed breast radiotherapy. Radiother Oncol. 2007;82(3):254-264.

55. Mulliez T, Speleers B, Madani I, De Gersem W, Veldeman L, De Neve $\mathrm{W}$. Whole breast radiotherapy in prone and supine position: is there a place for multi-beam IMRT? Radiat Oncol. 2013;8:151.

56. Kachnic LA, Powell SN. IMRT for breast cancer-balancing outcomes, patient selection, and resource utilization. J Natl Cancer Inst. 2011; 103(10):777-779.

57. Wang EH, Mougalian SS, Soulos PR, et al. Adoption of hypofractionated whole-breast irradiation for early-stage breast cancer: a National Cancer Data Base analysis. Int J Radiat Oncol Biol Phys. 2014;90(5):993-1000.

58. Start Trialists' Group; Bentzen SM, Agrawal RK, et al. The UK Standardisation of Breast Radiotherapy (START) Trial A of radiotherapy hypofractionation for treatment of early breast cancer: a randomised trial. Lancet Oncol. 2008;9(4):331-341.

59. Start Trialists' Group; Bentzen SM, Agrawal RK, et al. The UK Standardisation of Breast Radiotherapy (START) Trial B of radiotherapy hypofractionation for treatment of early breast cancer: a randomised trial. Lancet. 2008;371(9618):1098-1107.

60. Whelan TJ, Pignol JP, Levine MN, et al. Long-term results of hypofractionated radiation therapy for breast cancer. $N$ Engl J Med. 2010; 362(6):513-520.

61. Shaitelman SF, Schlembach PJ, Arzu I, et al. Acute and short-term toxic effects of conventionally fractionated vs hypofractionated wholebreast irradiation: a randomized clinical trial. JAMA Oncol. 2015;1(7): 931-941.

62. Bolderston A, Lloyd NS, Wong RK, Holden L, Robb-Blenderman L; Supportive Care Guidelines Group of Cancer Care Ontario Program in Evidence-Based C. The prevention and management of acute skin reactions related to radiation therapy: a systematic review and practice guideline. Support Care Cancer. 2006;14(8):802-817.
63. Boström A, Lindman H, Swartling C, Berne B, Bergh J. Potent corticosteroid cream (mometasone furoate) significantly reduces acute radiation dermatitis: results from a double-blind, randomized study. Radiother Oncol. 2001;59(3):257-265.

64. Miller RC, Schwartz DJ, Sloan JA, et al. Mometasone furoate effect on acute skin toxicity in breast cancer patients receiving radiotherapy: a phase III double-blind, randomized trial from the North Central Cancer Treatment Group N06C4. Int J Radiat Oncol Biol Phys. 2011; 79(5):1460-1466.

65. Omidvari S, Saboori H, Mohammadianpanah M, et al. Topical betamethasone for prevention of radiation dermatitis. Indian J Dermatol Venereol Leprol. 2007;73(3):209.

66. Ulff E, Maroti M, Serup J, Falkmer U. A potent steroid cream is superior to emollients in reducing acute radiation dermatitis in breast cancer patients treated with adjuvant radiotherapy. A randomised study of betamethasone versus two moisturizing creams. Radiother Oncol. 2013;108(2):287-292.

67. Ulff E, Maroti M, Serup J, Nilsson M, Falkmer U. Prophylactic treatment with a potent corticosteroid cream ameliorates radiodermatitis, independent of radiation schedule: a randomized double blinded study. Radiother Oncol. 2017;122(1):50-53.

68. Wells M, Macmillan M, Raab G, et al. Does aqueous or sucralfate cream affect the severity of erythematous radiation skin reactions? A randomised controlled trial. Radiother Oncol. 2004;73(2):153-162.

69. Williams MS, Burk M, Loprinzi CL, et al. Phase III double-blind evaluation of an aloe vera gel as a prophylactic agent for radiation-induced skin toxicity. Int J Radiat Oncol Biol Phys. 1996;36(2):345-349.

70. Heggie S, Bryant GP, Tripcony L, et al. A Phase III study on the efficacy of topical aloe vera gel on irradiated breast tissue. Cancer Nurs. 2002;25(6):442-451.

71. Pinnix C, Perkins GH, Strom EA, et al. Topical hyaluronic acid vs. standard of care for the prevention of radiation dermatitis after adjuvant radiotherapy for breast cancer: single-blind randomized phase III clinical trial. Int J Radiat Oncol Biol Phys. 2012;83(4):1089-1094.

72. Kirova YM, Fromantin I, De Rycke Y, et al. Can we decrease the skin reaction in breast cancer patients using hyaluronic acid during radiation therapy? Results of phase III randomised trial. Radiother Oncol. 2011;100(2):205-209.

73. Hemati S, Asnaashari O, Sarvizadeh M, et al. Topical silver sulfadiazine for the prevention of acute dermatitis during irradiation for breast cancer. Support Care Cancer. 2012;20(8):1613-1618.

74. Pommier P, Gomez F, Sunyach MP, D'Hombres A, Carrie C, Montbarbon X. Phase III randomized trial of Calendula officinalis compared with trolamine for the prevention of acute dermatitis during irradiation for breast cancer. J Clin Oncol. 2004;22(8):1447-1453.

75. Sharp L, Finnila K, Johansson H, Abrahamsson M, Hatschek T, Bergenmar M. No differences between Calendula cream and aqueous cream in the prevention of acute radiation skin reactions - results from a randomised blinded trial. Eur J Oncol Nurs. 2013;17(4):429-435.

76. Graham P, Browne L, Capp A, et al. Randomized, paired comparison of no-sting barrier film versus sorbolene cream ( $10 \%$ glycerine) skin care during postmastectomy irradiation. Int J Radiat Oncol Biol Phys. 2004;58(1):241-246.

77. Herst PM, Bennett NC, Sutherland AE, Peszynski RI, Paterson DB, Jasperse ML. Prophylactic use of Mepitel Film prevents radiationinduced moist desquamation in an intra-patient randomised controlled clinical trial of 78 breast cancer patients. Radiother Oncol. 2014; 110(1):137-143.

78. Graham PH, Plant N, Graham JL, et al. A paired, double-blind, randomized comparison of a moisturizing durable barrier cream to $10 \%$ glycerine cream in the prophylactic management of postmastectomy irradiation skin care: trans Tasman Radiation Oncology Group (TROG) 04.01. Int J Radiat Oncol Biol Phys. 2013;86(1):45-50.

79. Gaugler MH, Vereycken-Holler V, Squiban C, Vandamme M, VozeninBrotons MC, Benderitter M. Pravastatin limits endothelial activation after irradiation and decreases the resulting inflammatory and thrombotic responses. Radiat Res. 2005;163(5):479-487. 
80. Holler V, Buard V, Gaugler MH, et al. Pravastatin limits radiation-induced vascular dysfunction in the skin. J Invest Dermatol. 2009;129(5): 1280-1291.

81. Okunieff $\mathrm{P}, \mathrm{Xu} \mathrm{J}, \mathrm{Hu} \mathrm{D}$, et al. Curcumin protects against radiationinduced acute and chronic cutaneous toxicity in mice and decreases mRNA expression of inflammatory and fibrogenic cytokines. Int $J$ Radiat Oncol Biol Phys. 2006;65(3):890-898.

82. Xiao Z, Su Y, Yang S, et al. Protective effect of esculentoside A on radiation-induced dermatitis and fibrosis. Int J Radiat Oncol Biol Phys. 2006;65(3):882-889.

83. Fahl WE. Complete prevention of radiation-induced dermatitis using topical adrenergic vasoconstrictors. Arch Dermatol Res. 2016;308(10): 751-757.

84. Feight D, Baney T, Bruce S, McQuestion M. Putting evidence into practice. Clin J Oncol Nurs. 2011;15(5):481-492.

85. Wong RK, Bensadoun RJ, Boers-Doets CB, et al. Clinical practice guidelines for the prevention and treatment of acute and late radiation reactions from the MASCC Skin Toxicity Study Group. Support Care Cancer. 2013;21(10):2933-2948.

86. Campbell IR, Illingworth MH. Can patients wash during radiotherapy to the breast or chest wall? A randomized controlled trial. Clin Oncol. 1992;4(2):78-82.

87. Roy I, Fortin A, Larochelle M. The impact of skin washing with water and soap during breast irradiation: a randomized study. Radiother Oncol. 2001;58(3):333-339.

88. D'Haese S, Van Roy M, Bate T, Bijdekerke P, Vinh-Hung V. Management of skin reactions during radiotherapy in Flanders (Belgium): a study of nursing practice before and after the introduction of a skin care protocol. Eur J Oncol Nurs. 2010;14(5):367-372.

89. Frosch PJ, Kligman AM. The soap chamber test. A new method for assessing the irritancy of soaps. JAm Acad Dermatol. 1979;1(1):35-41.

90. Burch SE, Parker SA, Vann AM, Arazie JC. Measurement of 6-MV $\mathrm{X}$-ray surface dose when topical agents are applied prior to external beam irradiation. Int J Radiat Oncol Biol Phys. 1997;38(2):447-451.
91. Watson LC, Gies D, Thompson E, Thomas B. Randomized control trial: evaluating aluminum-based antiperspirant use, axilla skin toxicity, and reported quality of life in women receiving external beam radiotherapy for treatment of Stage 0, I, and II breast cancer. Int J Radiat Oncol Biol Phys. 2012;83(1):e29-e34.

92. Theberge V, Harel F, Dagnault A. Use of axillary deodorant and effect on acute skin toxicity during radiotherapy for breast cancer: a prospective randomized noninferiority trial. Int J Radiat Oncol Biol Phys. 2009;75(4):1048-1052.

93. Bennett C. An investigation into the use of a non-metallic deodorant during radiotherapy treatment: a randomised controlled trial. J Radiother Pract. 2009;8(1):3-9.

94. Gee A, Moffitt D, Churn M, Errington R. A randomised controlled trial to test a non-metallic deodorant used during a course of radiotherapy J Radiother Pract. 2000;1(4):205-212.

95. Aistars J. The validity of skin care protocols followed by women with breast cancer receiving external radiation. Clin J Oncol Nurs. 2006; 10(4):487-492.

96. Meegan M, Haycocks T. An investigation into the management of acute skin reactions from tangential breast irradiation. Can J Med Radiat Technol. 1997;29(43):169-173.

97. Winter GD. Formation of the scab and the rate of epithelization of superficial wounds in the skin of the young domestic pig. Nature. 1962; 193:293-294

98. Gollins S, Gaffney C, Slade S, Swindell R. RCT on gentian violet versus a hydrogel dressing for radiotherapy-induced moist skin desquamation. J Wound Care. 2008;17(6):268-270,272,274-265.

99. Mak SS, Molassiotis A, Wan WM, Lee IY, Chan ES. The effects of hydrocolloid dressing and gentian violet on radiation-induced moist desquamation wound healing. Cancer Nurs. 2000;23(3):220-229.

100. BC Cancer Agency [webpage on the Internet]. Symptom Management Guidelines: Radiation Dermatitis. Available from: http://www. bccancer.bc.ca/health-professionals/professional-resources/nursing/ symptom-management. Accessed November 8, 2016.
Breast Cancer - Targets and Therapy

\section{Publish your work in this journal}

Breast Cancer - Targets and Therapy is an international, peerreviewed open access journal focusing on breast cancer research, identification of therapeutic targets and the optimal use of preventative and integrated treatment interventions to achieve improved outcomes, enhanced survival and quality of life for the cancer patient.

\section{Dovepress}

The manuscript management system is completely online and includes a very quick and fair peer-review system, which is all easy to use. Visit http://www.dovepress.com/testimonials.php to read real quotes from published authors. 